\title{
Malakoplakia as a Rare Cause of Diarrhea: Case Presentation and Review of Literature
}

\author{
Mohammad Taher ${ }^{1}$, Reza Shahsia ${ }^{2}$, Nasser Ebrahimi Daryani ${ }^{3, *}$
}

1. Assistant Professor of Gastroenterology, Imam Khomeini Hospital Complex, Tehran University of Medical Sciences, Tehran, Iran

2. Associate Professor of Pathology, Imam Khomeini Hospital Complex, Tehran University of Medical Sciences, Tehran, Iran

3. Professor of Gastroenterology, Imam Khomeini Hospital Complex, Tehran University of Medical Sciences, Tehran, Iran

\section{* Corresponding Author:}

Nasser Ebrahimi Daryani, MD

No.130, Second floor; Next to Zafar St, Shahid Naseri St, Vali-e-Asr Ave, Tehran, Iran

Tel: + 982188793896

Fax: +982188799446

Email: nebrahim@sina.tums.ac.ir

Received: 05 Aug. 2020

Accepted: 13 Dec. 2020

\section{ABSTRACT}

Colonic malakoplakia is a rare chronic granulomatous disease that can involve many organs such as the lung, brain, pancreas, bone, adrenal glands, and genitourinary tract. The most common site of involvement outside the genitourinary tract is the gastrointestinal tract. We report a case of colonic malakoplakia who presented with unintentional weight loss, abdominal pain, and chronic diarrhea. There was a history of lupus nephritis and Sjogren disease, receiving various immunosuppressive drugs. Physical examination other than pallor was unremarkable in this patient, but colonoscopy revealed multiple polyps in the rectum with a cobblestone appearance in the cecum. The histopathological assessment showed infiltration of numerous lymphoplasma cells and neutrophils in the lamina propria, and rare Michaelis-Gutmann bodies were seen in foamy epithelioid histiocytes. These findings are suggestive of malakoplakia. We treated the patient with tetracycline, and after 3 months of follow-up, clinical improvement was achieved.

\section{KEYWORDS:}

Malakoplakia, Michaelis-Gutmann bodies, Chronic Diarrhea

Please cite this paper as:

Taher M, Shahsia R, Ebrahimi Daryani N. Malakoplakia as a Rare Cause of Diarrhea: Case Presentation and Review of Literature. Middle East J Dig Dis 2021;13:71-74. doi: 10.34172/mejdd.2021.207.

\section{INTRODUCTION}

Malakoplakia is a rare chronic inflammatory disease with unexplained etiology, which was first reported by Michaelis and Gutmann in 1902. ${ }^{1}$ It is characterized by tissue infiltrates of large granular macrophages termed Hansemann histiocytes or von Hansemann cells containing distinctive intracytoplasmic inclusions termed Michaelis-Gutmann (MG) bodies. ${ }^{2-4}$ Histiocytes contain periodic acid-Schiff positive and diastase resistant basophilic granules..$^{5}$ Immunostaining with polyclonal anti-mycobacterium bovis has been described as a method for identifying organisms in malakoplakia. ${ }^{6} \mathrm{MG}$ bodies represent the calcified detritus of incompletely digested bacteria within phagolysosomes; although considered pathognomonic, they are not always present. They may be intracellular or extracellular and are positive with the von Kossa stain for calcium and the Prussian blue stain for iron. ${ }^{5}$

The etiologies described for this disease include chronic bacterial infection (E.coli was found in more than two-thirds of cases), dysfunctional immune response, and abnormal lysosome function in macrophages. ${ }^{2,5}$ 

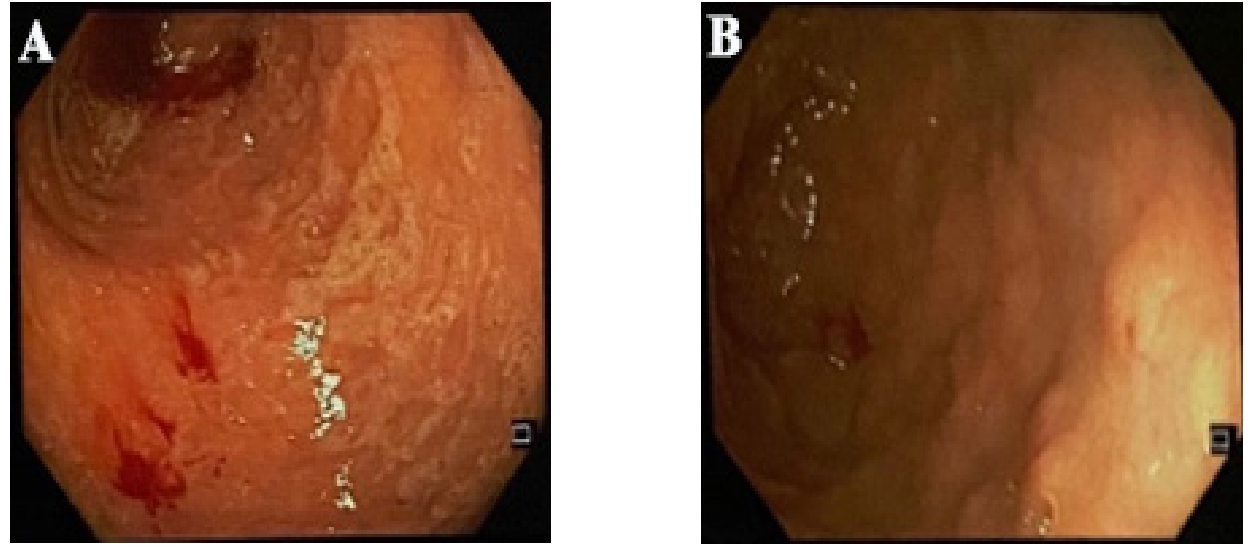

Fig.1: Colonoscopic findings: A) mucosal inflammation with cobblestone appearance in the cecum. B) multiple diminutive rectal polyps.

The most common involved organ is the bladder, followed by the gastrointestinal tract. ${ }^{2,3,5}$ There is a 4:1 female to male predilection for genitourinary tract involvement, but for other sites, there is no predisposition imparted by age, race, and sex. Although the average age at presentation is 50 years, patients have ranged from 6 weeks to 85 years old. ${ }^{5}$ Immunosuppression (solid organ transplant, human immunodeficiency virus, tuberculosis, and cancer) is a factor in the development of a number of cases. ${ }^{4,5}$ Because malakoplakia may occur as a complication of immunosuppression, whether primary or secondary, renal and liver transplant recipients are at risk. ${ }^{7}$

Herein, we present a case of a 58 -year-old man with unintentional weight loss, abdominal pain, and diarrhea who was found to have colonic malakoplakia. Colonoscopy revealed multiple diminutive rectal polyps and mucosal inflammation with cobblestone appearance in the cecum.

\section{CASE REPORT}

A 58-year-old man was referred to our clinic with the complaint of abdominal cramps and chronic diarrhea since 3 months earlier. He reported unintentional weight loss of about $10 \mathrm{~kg}$ during the 3 months. The patient had a history of Sjogren syndrome and lupus nephritis since 22 years ago, receiving various immunosuppressive agents, including mycophenolate mofetil, rituximab, tacrolimus $(4 \mathrm{mg} / \mathrm{d})$ since 2 years ago. He also used prednisolone $(7.5 \mathrm{mg} / \mathrm{d})$, hydroxychloroquine $(200 \mathrm{mg} / \mathrm{d})$, losartan (150 $\mathrm{mg} / \mathrm{d}$ ), and erythropoietin (4000 IU/SC three times a week). The patient denied recurrent infections, malnutrition, and other medical conditions. Routine blood work noted normochromic, normocytic anemia ( $\mathrm{Hb}: 8.6 \mathrm{gr} / \mathrm{dL}$ ), and elevated ESR (Erythrocyte sedimentation rate) (ESR: $39 \mathrm{~mm} / \mathrm{h})$ and creatinine (Cr: $1.3 \mathrm{mg} / \mathrm{dL})$. Tacrolimus level was $6.4 \mathrm{ng} /$ $\mathrm{mL}$. Other lab tests, including liver function tests and thyroid function tests, were normal. Negative results were reported for stool and blood cultures, ova and parasite testing, and Clostridium difficile toxin assay.

He underwent colonoscopy, which revealed multiple diminutive polyps in the rectum (two of them removed by jumbo forceps), mucosal inflammation, and cobblestone appearance in the sigmoid and cecum. Other parts of the colon appeared normal (figure 1 $\mathrm{A} \& \mathrm{~B})$.

CT enterography showed normal ileal and jejunal loops with normal wall thickness.

Histopathological examination of cecal mucosa and rectal polyps revealed crypt distortion, irregularity, and superficial erosions, and infiltration of numerous foamy epithelioid histiocytes, eosinophils, lymphoplasma cells, neutrophils, and occasional giant cells in the lamina propria. Foamy epithelioid histiocytes showed numerous PAS(Periodic Acid-Schiff) -positive granules in the cytoplasm. MG bodies were rarely seen. Microthrombi were also noted in the capillaries (figure 2 A \& B). These findings were compatible with colonic malakoplakia. As a treatment option, 


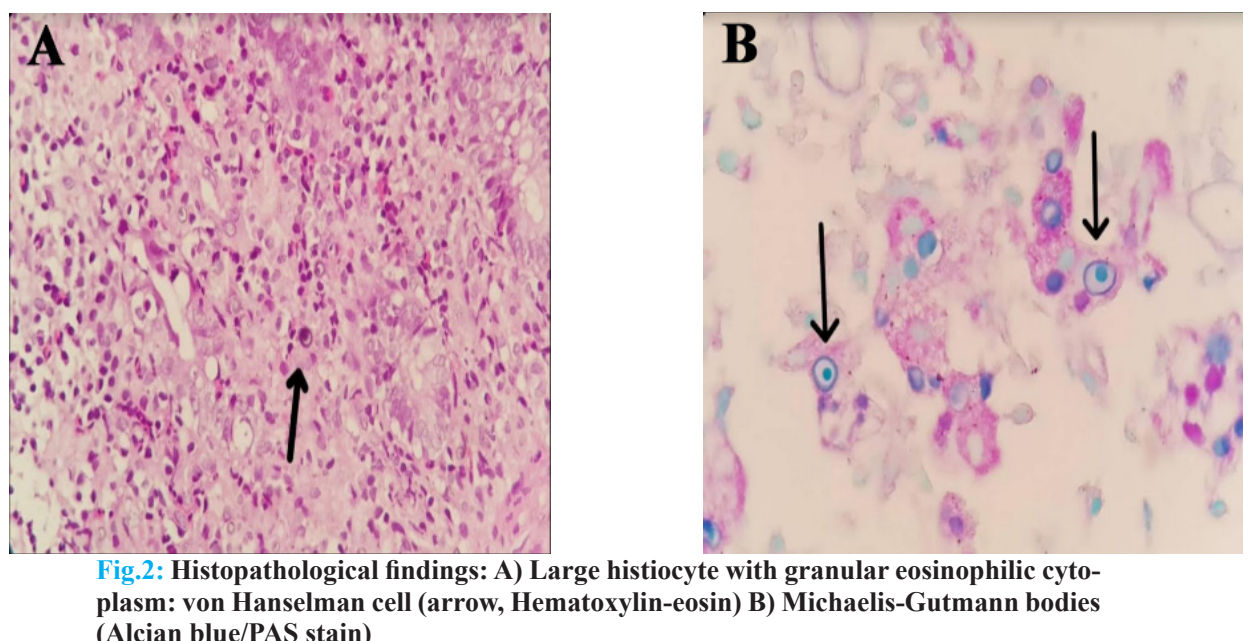

tetracycline was initiated, and immunosuppressive agents decreased, which were successful, and symptoms including diarrhea improved after 3 months of follow-up.

\section{DISCUSSION}

Malakoplakia, a term derived from the Greek adjectives "Malakos"(soft) and "Plaka"(plaque) implicated a rare chronic granulomatous disease. ${ }^{8}$ The disease is mainly diagnosed based on the characteristic feature of accumulated histiocytes having cytoplasmic inclusions, known as MG bodies. ${ }^{9}$ The most common site of involvement is the genitourinary tract, and the second most common site of involvement is the gastrointestinal tract. In most of these cases, the rectum, sigmoid, and right colon are involved. ${ }^{3,10}$ To our best knowledge, the etiology of malakoplakia remains unknown. Some pathogenic mechanisms such as infection, immunosuppression (immune deficiency disorders and organ transplantation), systemic conditions, malignancy, and genetic disorders. Some cases of malakoplakia associated with colon adenocarcinoma were described. ${ }^{3,11-13}$

Colonic malakoplakia can be asymptomatic or may be present with diarrhea, abdominal pain, rectal bleeding, intestinal obstruction, vomiting, malaise, fever, and constipation. ${ }^{5}$ Three patterns of the disease can be seen on colonoscopic examination: isolated rectosigmoid involvement with ulcers, plaques, and polypoid lesions; colonic stricture and intestinal fistula suggestive of associated cancer or Crohn's disease; and diffuse colonic involvement in immunosuppressed patients. Focal lesions may be associated with adenomatous polyps or cancer. ${ }^{14}$

Endoscopic differential diagnoses of colonic malakoplakia include malignancies, tuberculosis, and Crohn's disease. ${ }^{5}$ Pathologically, colonic malakoplakia could resemble whipple's disease, Wolman's disease, ${ }^{15}$ tuberculosis, sarcoidosis, and Chediak-Higashi syndrome. ${ }^{5}$

Escherichia coli is the most common pathogen isolated from over $90 \%$ of patients with malakoplakia. ${ }^{3}$ Due to the role of infection in malakoplakia, one of the treatment options for colonic malakoplakia is the administration of antibiotic agent with intracellular penetration such as trimethoprim-sulfamethoxazole, rifampicin, or quinolones. Bethanechol acts as a cholinergic agonist and increases intracellular levels of cGMP in macrophages ${ }^{16}$ In immunosuppressed patients, these agents should be decreased or stopped. ${ }^{17}$

\section{CONCLUSION}

Malakoplakia is a rare chronic inflammatory disease that occurs in a variety of anatomic sites. It is more commonly noted in patients that are immunosuppressed or suffering from chronic illness. It is a benign self -limited disease which can be treated with antibiotic agents.

Our presented case was a colonic malakoplakia associated with immunosuppression state who was treated with tetracycline $(500 \mathrm{mg} /$ twice daily $)$ and a decrease of immunosuppression agents. Clinical and radiological follow-up is necessary for these patients

\section{ETHICAL APPROVAL}

There is nothing to be declared. 


\section{CONFLICT OF INTEREST}

The authors declare no conflict of interest related to this work.

\section{REFERENCES}

1. Zanelli M, Ragazzi M, Serra S, Bellafiore S, Ascani S, De Marco L. Malakoplakia Associated With Multiple Adenomas of the Colon: An Extremely Rare Incidental Finding. Int J Surg Pathol 2016;24:548-51. doi: $10.1177 / 1066896916633855$.

2. Lewin KJ, Fair WR, Steigbigel RT, Winberg CD, Droller MJ. Clinical and laboratory studies into the pathogenesis of malacoplakia. J Clin Pathol 1976;29:354-63. doi: 10.1136/jcp.29.4.354.

3. McClure J. Malakoplakia of the gastrointestinal tract. Postgrad Med J 1981;57:95-103. doi: 10.1136/ pgmj.57.664.95.

4. Biggar WD, Crawford L, Cardella C, Bear RA, Gladman D, Reynolds WJ. Malakoplakia and immunosuppressive therapy. Am J Pathol 1985;119:5-11.

5. Yousef GM, Naghibi B, Hamodat MM. Malakoplakia outside the urinary tract. Arch Pathol Lab Med 2007;131:297-300. doi: 10.1043/1543-2165(2007)131[297:MOTUT]2.0.CO;2.

6. Mehregan DR, Mehregan AH, Mehregan DA. Cutaneous malakoplakia: a report of two cases with the use of anti-BCG for the detection for microorganisms. J Am Acad Dermatol 2000;43:351-4. doi: 10.1067/ mjd.2000.100538.

7. McKenzie KJ, More IAR. Non-progressive malakoplakia in a live donor renal allograft. Histopathology 1996;28:274-6. doi: 10.1046/j.1365-2559.1996.d01413.x.

8. Han SH, Joo M, Chang S, Kim HS. Malakoplakia affecting the umbilical cord. J Pathol Transl Med 2015;49:177-9. doi: 10.4132/jptm.2015.02.04.

9. Hyun KH, Shin HD, Kim DH. Malakoplakia in a healthy young female patient. Korean J Intern Med 2013;28:475-80. doi: 10.3904/kjim.2013.28.4.475.

10. Cipolletta L, Bianco MA, Fumo F, Orabona P, Piccinino F. Malacoplakia of the colon. Gastrointest Endosc 1995;41:255-8. doi: 10.1016/s0016-5107(95)70351-9.

11. Elie H, Maupin JM, Mandard JC. Malacoplakia in a rectal adenocarcinoma. Review of the literature. Apropos of a case. Ann Pathol 1983;3:333-6.

12. Karasavvidou F, Potamianos SP, Barbanis S, Stathakis E, Psychos A, Kapsoritakis AN, et al. Malakoplakia of the colon associated with colonic adenocarcinoma diagnosed in colonic biopsies. World J Gastroenterol 2007;13:6109-11. doi: 10.3748/wjg.v13.45.6109.

13. Sandmeier D, Guillou L. Malakoplakia and adenocarcinoma of the caecum: a rare association. J Clin Pathol 1993;46:959-60. doi: 10.1136/jcp.46.10.959.
14. Feldman M, Lawrence S, Friedman MD, Lawrence J, Brandt MDteE. Sleisenger and Fordtran's Gastrointestinal and Liver Disease. 10th ed. Philadelphia: Elsevier; 2016.

15. Perez-Atayde AR, Lack EE, Katz AJ, Geha RS Intestinal malakoplakia in childhood: case report and review of literature. Pediatr Pathol 1983;1:337-43. doi: 10.3109/15513818309040671.

16. Van del' Voort HJ, ten Velden JA, Wassenaar RP, Silberbusch J. Malacoplakia. Two case reports and a comparison of treatment modalities based on a literature review. Arch Intern Med 1996;156:577-83. doi: 10.1001/archinte.156.5.577.

17. van Furth R, van't Wout JW, Wertheimer PA, Zwartendijk J. Ciprofloxacin for treatment of malakoplakia. Lancet 1992;339:148-9. doi: 10.1016/0140-6736(92)90212-1. 